\title{
PROSPECTS OF SUSTAINABLE FASHION DESIGN INNOVATION
}

\section{RAJEEV KUMAR}

Lecturer, Department of Fashion Designing, Jayoti Vidyapeeth Women's University, Jaipur, India

\begin{abstract}
Fashion design leads toward a broader field rapidly with the contemporary socio-economic, political, and cultural diversity under the "people-oriented" principle. Modern fashion design integrated multi-angle, multi-paradigm. The multi aspect stands of severing to meet people's multi-angle, multi-paradigm. The multi aspect stands of severing to meet people's mental, physical, social and spiritual life. It opens up a new vision for modern fashion frontier and will be bound to the clothing design practice. The juncture of science and technology are undeniably having a profound effect on the fashion industry. The sustainable innovation in fashion is challenging in society, at the moment environmental apparel design and new positive system is needed for innovative designed to achieve sustainable fashion and eco-friendly materials. Textile ecology and eco-friendly material itself gives positive externalities to the society and not possesses any type of pollution to environment during the production of the garments. Green natural fiber, green regenerated fiber ecological organic cotton, bamboo fiber, color natural silk, soybean fiber, milk fiber, corn fiber and recycle fiber is the key sources of ecological garments. It is nontoxic to human body, but also is sociable in environment and beneficial to human. New synthetic high-tech materials emerge at a historic moment which has the environment protection and corresponds with consumption needs. These new materials make up the shortcomings of the traditional green fiber in function and make the clothing more comfortable, breathable.
\end{abstract}

KEYWORDS: Sustainable Innovation, Eco-friendly, Externalities \& Spiritual Life

Received: Sep 23, 2017; Accepted: Oct 12, 2017; Published: Oct 31, 2017; Paper Id.: IJTFTDEC20172

\section{INTRODUCTION}

Foods and non food items two important factor are necessary for human life. Cloths play vital role in non food items because it shows human behavior and image of human as well as physical from which is the most put up the shutters to human body. It used for covering, protecting and even decorating yourself. Every person must be having different types of clothes for different occasions like your casual attire, office wear, party dresses, and your night suit and so on. Its progress begin with the civilization and continued sustain yet. People every time demanded clothing for direct reflection and spiritual needs of human beings. This essentially determines the nature of fashion design based on "people-oriented" and the complete progressive tendency. Although the social material continuous abundance, it seems that the higher requirements of material and spiritual of clothing for human and more difficult to meet. This situate forward higher request to designers who have entered or will enter the garment industry. There is no doubt that people need to think deeply about future path of fashion design but modern fashion continuously diversify with the cultural economy and politics based on the essence of clothing and blended with the design concept of multi-angle, multi-paradigm. Eco-design is an important part of sustainable supply chains. With the increasing awareness of sustainability, eco-design has been a significant trend in the fashion industry. Many fashion brands such as Nike, Adidas, and The North Face have developed sustainable fashion by encompass 
eco-design elements. Fashion and textile is one of the most polluting industries in the world, every stage of the fashion and textile supply chain threatens our planet and resources, approximately 20,000 liter of water are consumed to produce per $\mathrm{kg}$ of cotton, many chemicals are used in manufacturing fabric for dyeing and finishing processes and production of one Tshirt generated large amounts hazardous chemicals $\left(\mathrm{CO}_{2}\right)$. Consumers are aware regarding significance of sustainability and are willing to purchase sustainable fashion products even though they are more expensive than conventional ones.

\section{OBJECTIVE OF RESEARCH}

The sustainable design strategies for fashion industry reduce the harmful effect of garment production. The sustainable design strategies turn out to be a solution of environmental problem. The objective of this research is to provide a solution of non-sustainability. In order to answer the main question, several subsidiary questions are formulated for the structure of the research:

- What is sustainability and how to reflect fashion industry today?

- How does garment appear in lifecycle?

- What types sustainable design strategies?

- How sustainable design strategies do reflects to professional fashion industry?

When conducting research for these sub questions first, a solid research framework is provided to eventually formulate an answer to the main research question.

- To comprehend the social, cultural and historical significance of fashion consumption in order to understand the challenge of sustainable consumption development.

- To develop a sustainable consumption practice that reduces 'fashion waste'.

- To evaluate the success of the clothing exchange as a fashion waste activation project and as an awareness raising exercise.

- To identify consumption and production patterns in the fashion industry.

- To identify the four pillars in sustainability: cultural, economic, environmental, and social responsibility.

- To identify a variety of sustainable materials (textiles and other materials pertaining to garment construction).

- To identify sustainable design processes and compare with non-sustainable fashion collection.

- To makes a divergence between classical made fashion collection and a sustainable fashion collection.

\section{Research Question and Purpose}

The research question of this paper is defined as; "How innovative are fashion companies to become sustainable?" In order to answer the question, the purpose is to make an evaluation among fashion companies by comparing them to each other in terms of their sustainability and to make out how innovative they are when the topic is functioning environmentally conscious. A mode of comparison, such as an index, can make the results of corporate social responsibility (CSR) attempts clear, which could lead fashion producers to act accordingly while creating transparency for consumers. The main focus of this research is on the environmental side of sustainability due to the incapability of 
evaluating social and economical aspects. Consumer perspective is commonly used as a parameter to rank the brand values of companies. Therefore, when the results of desk research and expert interviews are compared the consumer viewpoint will act as evidence. The sustainability and innovation are very specific areas and mass of consumers might not be aware of these subjects, because of this failure of consciousness, the survey for the research is applied on a group to be able to reach a more acknowledge this group is called "Informed Consumers" and the public opinion mentioned through the paper represents the public view of this informed group. While conducting a desk research analyses on the some fashion brands and their sustainability. However, it could not reach any evaluation or mapping of fashion brands and build a new model, which considers both sustainability and innovativeness as the equity of several brands. In the light of this indicator, it could be possible to observe if there is relative between the business models and the innovation within sustainability. This model can be dynamic which means that it can be improved and updated. The model can lead both companies and consumers to think about sustainability from a closer perspective while increasing the transparency of fashion providers.

\section{Key Factors of Sustainability that Need Addressing in the Clothing Supply Chain}

- Animal welfare- ensuring that good standards are upheld during leather and wool production.

- Chemicals in the working environment can be toxic and damage workers' health and the local environment.

- Energy consumed when we are washing our clothes contributes to climate change.

- Fashion consumption- the increasing number of fashion items that we buy and then dispose of.

- Fashion miles that burn carbon as fabric and clothing are transported around the world.

- The intensity of cotton production requiring lots of energy, water and pesticides.

- Unsustainable man-made fibers can take longer to degrade in landfill sites.

- Working conditions across the supply chain from cotton production.

\section{SUSTAINABLE DESIGN OF CLOTHING ART}

The awareness of sustainable development has won support among the people. Ecological environmental clothing has become a new hot pursuit of fashion. The negative effects caused by the modern life are increasingly reflected. Many disastrous irreversible trends make human survival at stake in the short-term, such as global warming, air, water land pollution and energy depletion. People no longer blindly pursuing economic benefits, but gradually realize the importance of ecological and environmental protection is more in-depth in people's life and production. Environmental protection clothing design has become a powerful trend, in order to meet people's physiological needs of health and hygienic and sustainable psychological needs. This feature is what we must grasp in the fashion design.

\section{The Fast-Changing of Eco-Friendly Materials}

Environmental clothing design needs eco-friendly materials. From the point of view of textile ecology, ecofriendly materials itself is not contaminated and won't cause pollution to the environment in the process of production. It is not only harmless to human body, but also is friendly to environment and beneficial to humans. No wonder green natural fiber and green regenerated fiber have been used in the environmental clothing. Ecological organic cotton, bamboo fiber, color natural silk, soybean fiber, milk fiber and corn fiber have been widely used in life. At the same time, human has 
injected the traditional fibers into high-tech. Some new synthetic materials emerge at a historic moment which has the environment protection and corresponds with consumption needs. These new materials make up the shortcomings of the traditional green fiber in function and make the clothing more comfortable, breathable and functional.

\section{Return to the Combination of Traditional Crafts and Modern Technology}

The combination of science, ethics and aesthetics spirit makes people pay more attention to the production of green clothing, which gradually raises a hot wave of technology back to nature in the world. The combination of traditional crafts and modern technology make environmental clothing more wonderful from the designers. People use natural dyes and dyeing fabrics by hand. By weaving, knotting, embroidering, wrinkling, topstitching, pulling the net, beading, tiedying, batik, bonding, stitching, hollowing out and other traditional decoration crafts, it can change and enhance the appearance of the fabric. The modern seamless splicing, digital printing and laser cutting technology can make up some limitations in the traditional craft. It is not only environmental protection, but also can greatly improve the efficiency of the clothing production. The combination of the two has realized the product of renewability and recyclability. It has realistic significance for green clothing and high economic and environmental value for the further research and development. Fabric reconstruction is the extension of designer's idea. It is a secondly innovative design to the fabric. In order to meet the need in design, on the basis of the aesthetic principle, it makes the finished fabric secondary processed. It merges the combination of traditional crafts and modern technology to generate a new artistic effect. This greatly reflects the theme of green design and has realized the reuse of fabric. Not only it can save resources, but also is low-carbon green. Making use of traditional handicrafts and different methods to secondary design of fabric and building new fashion space is to get more rich fabric effect and make the requirements of environmental protection clothing.

\section{Recreation of Green Textile}

Recently, the famous British designers cooperate with scientists to make plastic clothes which will dissolve in the water. The inventor's original intention is to let people pay more attention to environment. At the same time, it is better to make use of clothing to protect environment. This kind of clothing is made by Helen Dorian, a professor of London College of fashion, and Tony Ryan, a professor of Sheffield Interaction Research Center of British University. They are trying to find a way to reduce discarded clothes are sent to landfills resulted in pollution and waste. This kind of plastic clothes is made from biodegradable polyvinyl alcohol, as well as capsule will dissolve in the water. It is reported that researchers are working on another project-Designing "contact reaction clothing". They expect to control the pollutions with the surface of the garment. And then washing and neutralizing. As Dorian said, the clothes have a large surface area which can be used to purify the air.

\section{Growing Impacts of Climate Change}

In coming years the way the climate changes will be critical in shaping our future, because of the time lag in impacts of present and past estimations on the climate, most of the climate change that we will experience in 2025 is the result of past pollution. Action between now and 2025 will do little to alter the way the climate changes. The planet will experience real disruption as a result of climate change in the next 8 years. Individuals and communities, especially in lowincome countries are already experiencing elevated levels of environmental stress as a result of climate change. The changes to the climate that the world experiences after 2025 will depend on how we respond to climate change over the next 8 years. This is different in each our scenarios and they would present radically different climate impacts later in 
the century.

\section{How will Society Respond to Resource Scarcity and Climate Change?}

How our societies responds to resource shortages and climate change will depend on a complex set of factors including the willingness of people and business to change their behavior and the ability of politicians to reach global collective agreements. Public attitudes will play a key role. How much will people be willingness to make lifestyle choices that reduce consumption to reduce pressure on the environment? Will radical behavior change occur in pursuits of lowcarbon/impact living? Could we see a shift in values, with people concerned less with consumption and more with wellbeing and quality of life? Slow is a beautiful present a world in which there has been such a shift in values. In TechnoChic a technological response to resource shortages and climate change allows consumption to continue to drive the economy. The public perception of resource scarcity and climate change will play an important role in influencing the critical political responses to these problems. Whether stages go for market-led responses or regulatory incentives will have a big impact on businesses and the role they play. Working with the markets could lead to businesses harnessing innovation to deliver transformation, such as those seen in Techno-Chic.

\section{Ethics and Aesthetics}

\section{Values and Green Aesthetics}

Values and ethics are fundamental grounds for sustainable fashion. It would be fruitful for designers to consider whose values are included in the design process and on what basis. It is also good to remember that there isn't any value free design. We should design and construct a new system and basis for value creation, to help us face future challenges in the sustainable fashion discipline. Such a system could serve to evaluate design proposals and their benefits for sustainable development. Furthermore manufacturing processes, business models and marketing could be included in this value evaluation process. Green aesthetics is an approach that combines aesthetic experiences and evaluation with sustainable values, and it offers an opportunity to mature our aesthetic experiences in the context of fashion.

\section{Value Creation}

Design forms an integral part of our culture and values within. This means that sustainable design should not only take into account economic values, but cultural, social, ethical and environment values should also be included in the sustainable design process. Designing could change and become a more proactive and participatory process aiming for aesthetics sustainability. To this ambition it can be added that sustainable design can also be proactive process that aims to transform consumption patterns toward more sustainable ones and therefore it includes future oriented thinking. It is important to understand how current design, manufacturing and business practice affects unsustainable consumption patterns. Products actually configure consumers' needs and use patterns and hence design can be said to be "practiceoriented", which leads to certain everyday consumption habits. Therefore designers, manufacturers and companies are responsible not only for environmental impacts of the fashion industry but also for unsustainable consumption behavior of consumers. Designers can even destroy the value of the product by creating fast-changing trends that quickly outdate the products and render them valueless. The product itself may destroy something valuable, such as a craft skill or local knowledge and something already have seen in the area of fashion. Manufacturing locations are far from end markets and local manufacturing skills have diminished or disappeared. At the same time only few consumers can repair their own garments or have skills to create garments themselves; many do not even own sewing machine. Future-oriented value 
creation as an approach guides designers and manufacturers towards farsighted products and far-sighted business thinking, transforming current practices towards more sustainable societies.

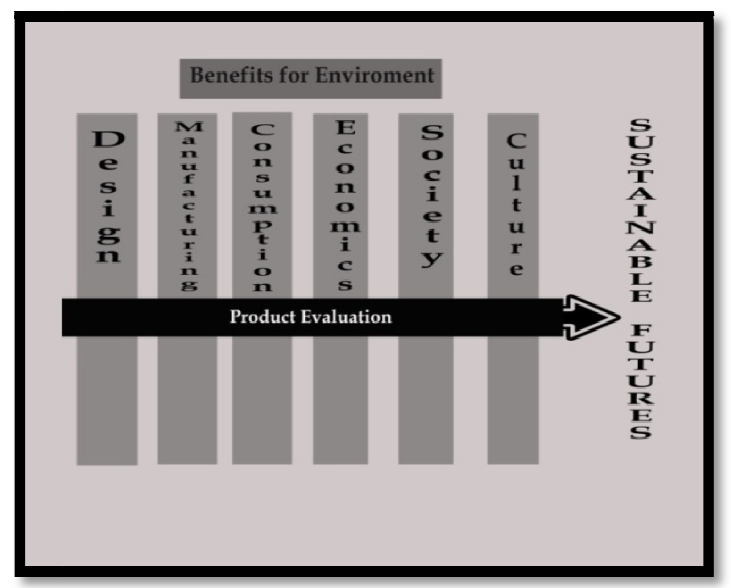

Figure 1: Future-Oriented Product Value Evaluation

Figure 1 shows the future-oriented value in fashion system. All design and manufacturing decision has to include consideration of the future: how the product will be used, how it will age and how it will be disposed of. Moreover the business model and its influence on consumption practices are included in this evaluation process. All these aspects have to be considered before the product is designed or manufactured. And is there the possibility to completely avoid materialistic consumption and do business differently. Radical thinking is needed to create a new value creation process in sustainable fashion. At the best, a new kind of sustainable fashion system can create value for people; planet and profit (Figure 2.)

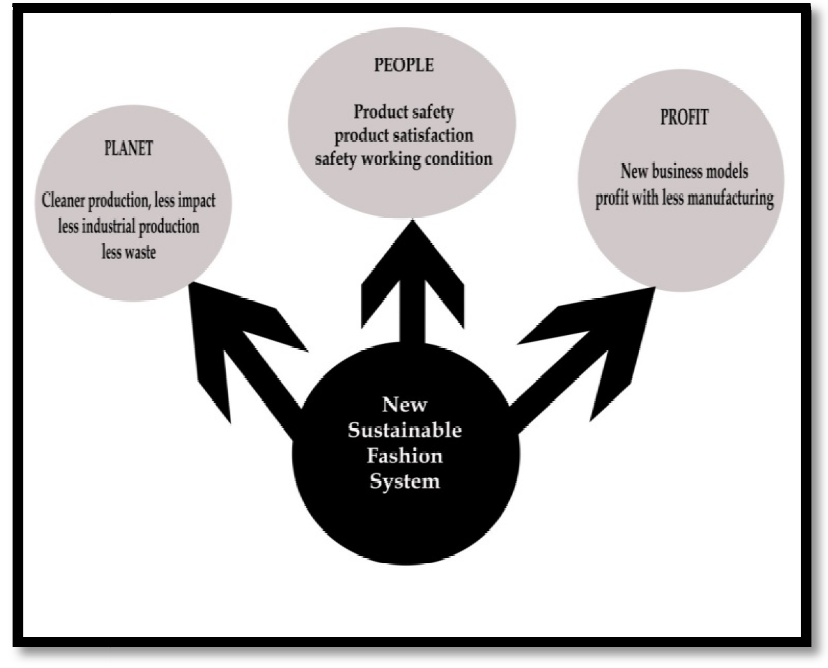

Figure 2: Sustainable Fashion System can Create Value for People, Planet Business

The system can create a safe environment through the use of fewer chemicals in production. This system can also promote greater product satisfaction through better quality and longer lasting products. It can promote well being and happiness through better quality and longer lasting products. It can promote well being and happiness through less materialistic consumption. The top quality and more expensive products, use them longer, own less and take good care of fashion professions. Moreover such system is able to more social justice and better working conditions for textile factories' workers, despite the fact that slowing the system it is possible to increase the end price of product and invest in better 
factories. For the environment, through cleaner production and perhaps even less industrial production and waste, the benefits for slower cycles are clear. For new business models to build return in an environmentally beneficial way have to be created. New systems accepted wisdom for these radical green business models to encourage less materialistic industrial manufacturing.

\section{Role of Aesthetics Sustainability in Fashion}

Garments are primarily to cover our bodies and stay warm. We may have to wear particular professional clothes for cultural reasons. This support our identity or as a sign of belongings to a certain group. There are several causes for what we choose to wear, but in a lot of cases choices are guided by the look that clothing creates the aesthetics. In the present day, there is certainly no lack of choice in clothing. Various fashion chains propose good looking garments at very reasonably priced. At the same time, through the joint effort of researchers, media and activists, the awareness of the problematic environmental and ethical issues in the clothing and textile industry has risen, such as pollution and unfair working conditions. Therefore even companies usually seen as fast fashion usually seen as fast fashion are increasingly including sustainability in their agendas. For example, H\&M is committed to "provide fashion for conscious customers" and "use natural resources responsibility" with its conscious line. However as in H\&M's case, the speed of change that is being promoted by suspiciously cheap clothing constantly new products, frequent sales, and excessive marketing is anything but sustainable. The small consumption is one approach to ascertain more sustainability in fashion. As aesthetics play such an important role in clothing choice, it matters equally in the context of sustainability. In terms of developing attachment to clothing and therefore lengthening their lifespan, the aesthetics dimension is sustainable.

\section{Ethical Fashion}

The possibilities of ecological and ethical garments choices are inadequate and designers and producers do what they can, a situation that can be described as realistic thinking. This kind of value-based, yet realistic, approach to sustainable fashion is the most common approach currently existing in the business. Best practice can be defined to mean that designers and companies choose the best environmental and social solution that exists; particularly small and medium size companies have to make their choices from limited possibilities. Sustainable eco-materials that can be ordered in small amounts, to give only one example, can be most challenging for small companies. Accordingly available resources create the action framework for sustainable oriented designers: i.e. what kinds of design and production choices they can make. The bigger the fashion company, the more power and possibilities they have to influence sustainable practices in the field.

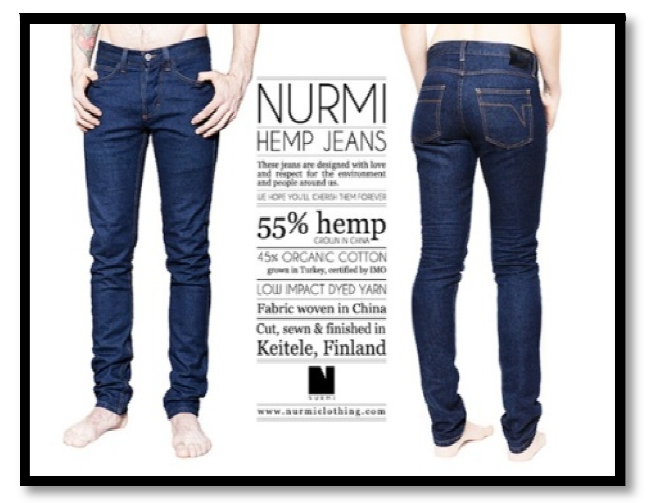

Figure 3: NURMI Hemp Jeans Photo Courtesy: Nurmi Hem Jeans (Photo: Antti Ahtiluoto) 


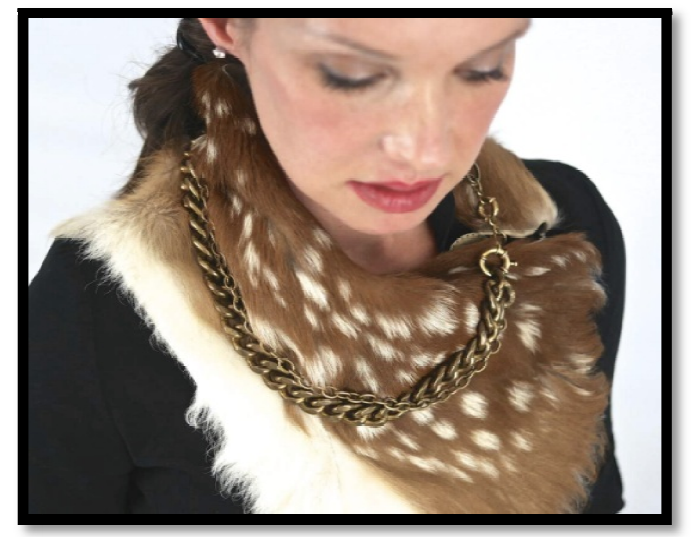

Figure 4: Ethical Fur, Photo Courtesy: Mother Nature Network (Photo: Starre Vartan)

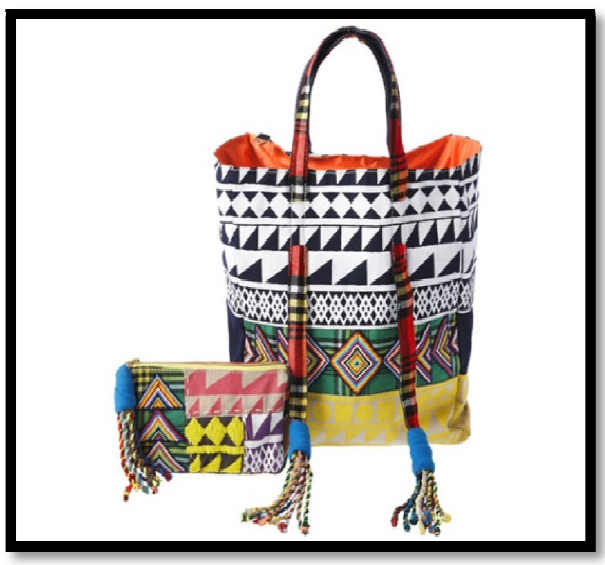

Figure 5: Ethical Luxury, Photo Courtesy: MAGNIFECO from HARPER's BAZZAR

\section{CONCLUSIONS}

The fashion design is a multi-disciplinary comprehensive art and technology drives the rapid development of clothing skill. Modern science and technology supported people-oriented fashion design. It develops forward to meeting people's physiological needs. Nowadays, multicultural, environmental protection and intelligent digitization become one of the most efficient themes of the fashion design. The rapid development of the network information makes clothing design more efficient. People's demands for environmental health gradually achieve the integrative development of better health. The frontiers of modern garment design art, exploring a new perspective of modern art of clothing, starting from the multiangle and multi-dimensional unceasingly, communicating with multi-culture and setting up a new conception of taking health as the centre all that are to lead the fashion design to a broader field with the backing of a strong technical force. Sustainable fashion must fundamentally be based on values and ethics. This is a challenging process and needs new awareness, a lot of information, and wide and open collaboration with various partners; more future-oriented thinking might help us in this process of planning a gauging how our design will affect consumption and environment. People wear is connected to the cultural and sub-cultural surroundings, as well as to the current time. Clothing serves many functions from covering the body to building identity, and aesthetics play a significant role. However the textile and clothing industry has a huge environmental impact and faces numerous ethical issues. The high volumes of waste, both in the manufacturing phase and in the disposal of products, indicate that slowing down clothing consumption and cultivating the longevity of clothing is essential. Although practically grounded solutions such as sustainable production methods bring 
tangible benefit, aesthetics must be taken into account in order to create clothing that people want to wear. The aesthetics dimension is also fundamental for people forming attachments to clothing, valuing and taking care of it, thus lengthening its lifespan, cultivating longevity, and promoting the ideals of sustainability. Therefore, it is important that both issues, the practical methods and aesthetics, are addressed together to meet sustainability goals in fashion. Designers' and companies' reality today is that they have to make their choices from the limited possibilities and offerings that exist on the current market, the end design result is not always the ideal or perfect one. Yet we need strong and brave designers and companies who question today's practice and examine how to do things differently. Moreover these change-makers can demand sustainable change from their suppliers, subcontractors or manufacturers and through this pressure create change in the fashion industry.

\section{REFERENCES}

1. Aakko, M. (2013). Sustanable fashion new apporoches. Retrieved september 20, 2017, from https://shop. aalto. fi/media/attachments/lee80/SustainableFashion. pdf

2. Anderson, J. (2010). Fashion future. Retrieved september 15, 2017, from https://www. forumforthefuture. org/sites/default/files/project/downloads/fashionfuturespresentationpdf. pdf

3. Muslu, D. (2014). INNOVATION AND SUSTAINABILITY IN FASHION INDUSTRY. Retrieved august 10, 2017, from http://bada. hb. se/bitstream/2320/12262/1/2012.13.14.pdf

4. Chunyan, Q., \& Yue, H. (2014). The Research and Development of the Future Fashion Design. Retrieved august

5. SOOCHETA, A. V. (2016). SUSTAINABLE FASHION: DESIGNRESEARCH INNOVATION. Retrieved august 17, 2017, from http://www.textileassociationindia.org/wp-content/uploads/2016/09/2-III\%20-Sustainable\%20Fashion\%20 \%20Design.\%20Research\%20and\%20Innovation\%20(Dr.\%20Anagha\%20V.\%20Soocheta).pdf 
